\title{
Amyloid- $\beta$ imaging with PET in Alzheimer's disease: is it feasible with current radiotracers and technologies?
}

\author{
Mateen C. Moghbel • Babak Saboury • Sandip Basu • \\ Scott D. Metzler • Drew A. Torigian • \\ Bengt Långström • Abass Alavi
}

Published online: 19 October 2011

(C) Springer-Verlag 2011

\section{Introduction}

Although it afflicts an estimated 26.6 million people worldwide - a figure that is expected to quadruple by 2050-Alzheimer's disease (AD) has yet to be fully understood etiologically, diagnostically, or therapeutically [1]. For decades, the most widely accepted definite diagnosis of $\mathrm{AD}$ has been the histological observation of

M.C. Moghbel and B. Saboury are co-first authors.

M. C. Moghbel • B. Saboury · S. D. Metzler · D. A. Torigian •

A. Alavi $(\square)$

Department of Radiology, Hospital of University of Pennsylvania,

3400 Spruce Street,

Philadelphia, PA 19104, USA

e-mail: abass.alavi@uphs.upenn.edu

M. C. Moghbel

e-mail: mateen.moghbel@uphs.upenn.edu

B. Saboury

e-mail: babak.saboury@uphs.upenn.edu

S. Basu

Radiation Medicine Center (BARC), Tata Memorial Hospital,

Mumbai, India

B. Långström

Department of Biochemistry and Organic Chemistry,

Uppsala University,

Uppsala, Sweden

B. Långström

Department. of Nuclear Medicine,

University of Southern Denmark,

Odense, Denmark

B. Långström

Center for Pharmacology and Therapeutics,

Neuropsychopharmacology Unit, Imperial College,

London, UK

senile plaques composed of amyloid- $\beta(A \beta)$ and neurofibrillary tangles comprising tau [2-4]. Theories abound as to the mechanisms behind these deposits of $A \beta$ and tau, one of the most prominent of which is the "amyloid hypothesis." This hypothesis proposes that the cleavage of amyloid precursor protein by $\beta$-secretase and $\gamma$-secretase causes $\mathrm{A} \beta 42$ to accumulate as senile plaques, which results in synaptic and neuronal injury [5].

The credence afforded to the amyloid hypothesis has spurred the development of a number of tracers intended to reflect the burden of amyloid plaques in $\mathrm{AD}$ patients in vivo and non-invasively with positron emission tomography (PET). The earliest amyloid imaging agents, including $\left[{ }^{11} \mathrm{C}\right]$ $\mathrm{PiB}$ and $\left[{ }^{18} \mathrm{~F}\right] \mathrm{FDDNP}$, were designed and tested in the earlyto-mid part of the last decade, and have been limited to research studies. However, the advent of three new radiotracers, which are currently at various stages of FDA assessment and approval, has brought amyloid imaging to the doorstep of clinical use. Recent clinical studies on florbetapir (AV-45), florbetaben (BAY-94), and flutemetamol (GE-067) claim to have demonstrated an ability to discriminate between $\mathrm{AD}$ patients and healthy controls with high degrees of sensitivity and specificity [6-11]. However, the theoretical bases of and ubiquitous patterns in the reported data raise a host of lingering questions that should be addressed before these radiotracers are clinically approved.

\section{Anomalies in the distribution of amyloid radiotracers}

One of the more troubling aspects of amyloid imaging is the striking discrepancy in the distribution of $A \beta$ deposits in the brain between PET images produced with amyloid tracers and histopathological and immunohistochemical studies, which should be - and have been - held up as the reference standard. A phase III study of florbetapir by Clark 
et al. reported significant correlations between quantitative and semiquantitative measures of overall amyloid burden through imaging and histopathology, but the regional localizations of these amyloid deposits do not seem to agree with pre-existing pathological data [5]. Imaging studies conducted with florbetapir, as well as virtually any other amyloid radiotracer, consistently show the frontal lobe to have one of-if not the-highest standardized uptake values (SUVs) [6, 8, 9, 11-14]. This implies a preponderant amyloid burden in the frontal lobe, which is not in line with the findings of in vitro studies.

By contrast, a comprehensive histopathological survey of the cortices found the highest density of neuritic plaques in the temporal and occipital lobes, an intermediate accumulation in the parietal lobe, and the lowest concentration in the limbic and frontal lobes [15] (Fig. 1). A similar pathological study of 2,661 autopsy cases found that amyloid plaques are concentrated in the temporal gray matter and the perirhinal and ectorhinal fields in early $\mathrm{AD}$, and do not spread to the frontal lobe until later stages of the disease [16]. A study of cerebral degeneration, which is considered by the amyloid hypothesis to be a direct consequence of $A \beta$ deposition, pinpointed the medial temporal cortex as the epicenter of neuronal deterioration, with damage radiating first and foremost to the parietal and occipital areas. In this cascade of neurodegeneration, the frontal lobe is shown to occupy only an intermediate position [17].

This point has been well illustrated in scans conducted using other imaging modalities, as well as PET with nonamyloid tracers. Magnetic resonance imaging (MRI) scans of $\mathrm{AD}$ patients reveal the greatest degree of atrophy in the temporal and parietal lobes, with frontal lobe damage delayed until the late stages of the disease [18-20]. Likewise, functional MRI studies have shown that the most pro- nounced differences in blood flow between AD patients and controls occur in the temporal and parietal lobes [21]. Even PET, when measuring the glucose metabolism of the brain with $\left[{ }^{18} \mathrm{~F}\right]$ FDG rather than its amyloid burden, exhibits a similar pattern of hypometabolism in the parietotemporal region, where over $50 \%$ of metabolic reductions occur [2224]. With this compelling and diverse set of evidence in mind, the preferential uptake in the frontal lobes that is invariably exhibited by amyloid imaging agents raises questions about the specificity of these radiotracers. These issues are further underscored as the phase III florbetapir study showed that the frontal lobe has one of the lowest correlations between measures of amyloid burden through in vivo imaging and at autopsy through histopathology [7].

The findings in the frontal lobe seem to suggest non-specific binding by the amyloid agents, but there may be an alternative explanation: the distribution of cerebral amyloid angiopathy (CAA), a condition involving an accumulation of $A \beta$ in the vasculature of the brain, is distinct from that of AD. CAA is most frequently associated with the arteries of the frontal and occipital lobes $[25,26]$. It is also far more common in $\mathrm{AD}$ patients, with reported comorbidity rates between $82 \%$ and $87 \%$, than in non-AD individuals, in whom incidence rates between $26 \%$ and $30 \%$ have reported [27-29]. Thus, the prevalence of CAA in AD patients could account not only for the observation that uptake of amyloid agents in the frontal lobes is unexpectedly one of the highest, but also that the difference in uptake between $\mathrm{AD}$ patients and controls is most pronounced in the frontal lobe [9].

However, CAA cannot explain another anomaly in amyloid imaging: the substantial uptake of radiotracers in the white matter of the brain, which is believed to be nearly devoid of $\mathrm{A} \beta$ plaques. PET images produced with amyloid agents consistently show higher ratios of white matter to

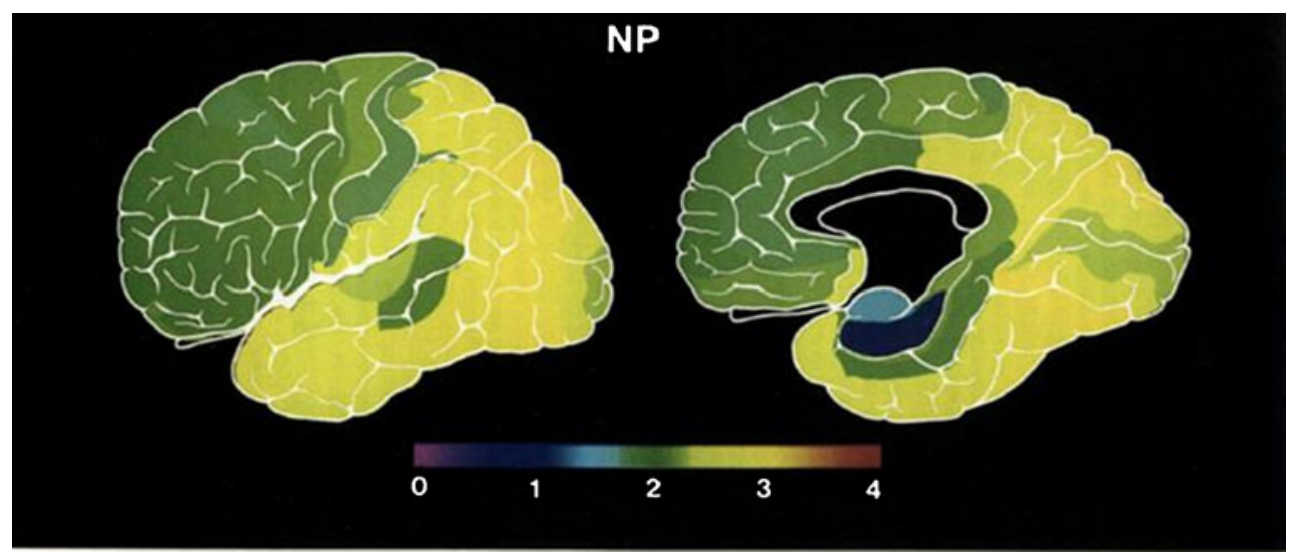

Fig. 1 Neuroanatomical distribution of neuritic plaques in the brain of $\mathrm{AD}$ patients, as revealed by histopathological and immunohistochemical staining. The amyloid burdens are rated on an arbitrary scale of 0 (lowest) to 4 (highest). The typical histopathologically observed pattern of comparatively high concentrations of amyloid in the temporoparietal lobes and the low concentrations in the frontal lobe should be noted and contrasted against the contradictory distribution pattern captured by amyloid imaging (reproduced with permission from Cerebral Cortex, [15]) 
gray matter uptake than immunohistochemical tests [30]. This pattern of white matter uptake of amyloid radiotracers has been largely described as a product of non-specific binding, but has also been speculated to be an artifact of a slower clearance rate due to lower blood flow in the white matter than in the gray matter $[30,31]$. The proposed dependence of tracer concentration on blood flow is supported by the observed relationship between cerebral blood flow and influx of $\left[{ }^{11} \mathrm{C}\right] \mathrm{PiB}$ into the brain [32]. Furthermore, it has been postulated that high radiotracer uptake in the gray matter of $\mathrm{AD}$ patients may spill over into the white matter, thereby artificially inflating SUVs [30]. This may not be able to explain the inordinately high uptake in the white matter of control subjects, and in fact raises the possibility of uptake in the white matter of controls spilling over into the gray matter (Fig. 2). This appears exceedingly likely considering the susceptibility of structures as small as amyloid plaques to the partial-volume effect, which is seen in most imaging modalities, including PET [33].

\section{Difficulties in visualizing amyloid plaques}

The relatively poor spatial resolution of PET is associated with the phenomenon of the partial-volume effect, which results in the underestimation of a structure's SUV. This effect is especially severe for structures that are less than 2.5 times the spatial resolution of the PET system, as measured by the full-width at half-maximum [35]. Since

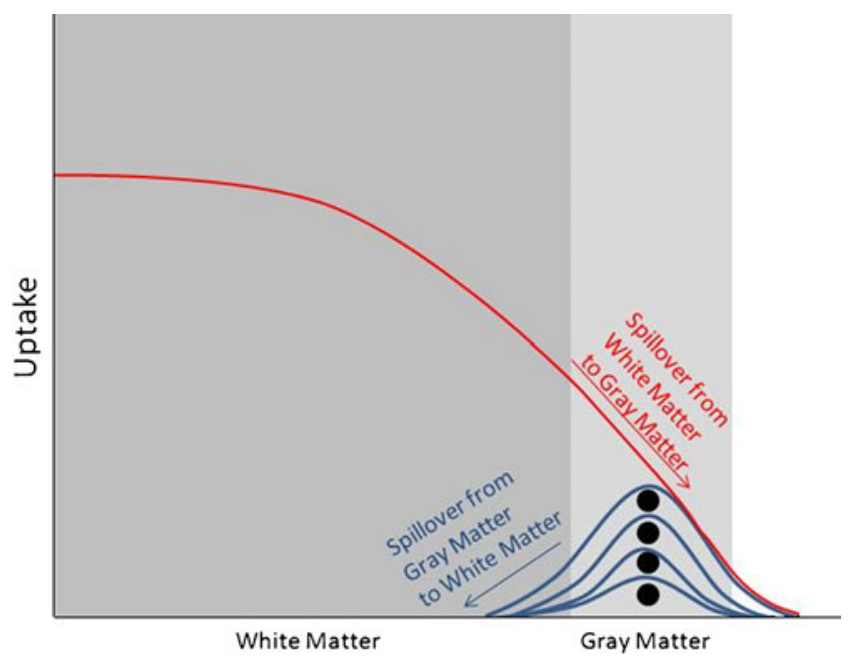

Fig. 2 Uptake in the white matter of the brain spilling over into the gray matter, and vice versa, using typical uptake profiles for PET imaging [34]. The black circles represent increasing proportions of cortical area occupied by $\mathrm{A} \beta$, while the blue lines signify the uptake profiles at these respective amyloid burdens. The red line illustrates the substantial radiotracer uptake observed in the white matter, which will unavoidably overwhelm the signal from the gray matter at mild to moderate amyloid burdens amyloid plaques are, on average, approximately $50 \mu \mathrm{m}$ in diameter and the spatial resolution of PET is normally in the range of 2 to $3 \mathrm{~mm}$ for high-resolution systems and 5 to $7 \mathrm{~mm}$ for standard scans, the partial-volume effect should theoretically be factored heavily into amyloid imaging and should not be overlooked [36, 37]. And yet Wong et al. explicitly state that in a phase I clinical study of florbetapir partial-volume correction was not undertaken in the analysis of data [6]. The reports of other studies on amyloid radiotracers make no mention of partial-volume correction, suggesting that this highly significant effect was also neglected in these studies. The result of this would be a prevalence of underestimated SUV data in the literature.

Perhaps the most fundamental question about amyloid imaging concerns the ability of PET to visualize $A \beta$ deposits. In area 9 of the frontal cortex - a region demonstrating remarkably high uptake of amyloid radiotracers - the percentage of total area occupied by amyloid plaques was shown by one histopathological study to be approximately $7.11 \%$ in AD patients [38]. Similarly, the histopathological component of the phase III florbetapir study found that the average amyloid burden in the precuneus, another region of high uptake, was $5.24 \%$ in nine patients for whom $\mathrm{AD}$ was named as the cause of death [7]. If it is assumed that amyloid burden in end-stage $\mathrm{AD}$ constitutes roughly $6 \%$ (in terms of area fraction) of the most severely affected cortical regions, and that the contrast between plaque and background must be at least twofold in order to visualize these structures with PET, the differential uptake of these amyloid tracers must be at least 100 times greater in amyloid plaques than in the background (Appendix; Fig. 3). This estimate would be considerably higher in regions with less amyloid burden, as well as in patients with less advanced $\mathrm{AD}$, in whom amyloid imaging would presumably be most diagnostically valuable. For example, in patients with mild cognitive impairment (MCI)/ prodromal $\mathrm{AD}$, in whom the amyloid burden would be closer to $0.1 \%$ of the area involved (equivalent to $0.03 \%$ of the total volume involved), the differential affinity for amyloid would have to be at least 6,000 times that of the background. This is a tall order for any radiotracer, but seems especially unlikely for amyloid imaging agents considering the extent of their non-specific uptake in the white matter, as well as other regions in the gray matter.

\section{Binding properties of amyloid plaques}

The conspicuous discrepancies between in vivo imaging and in vitro testing in the white matter and frontal lobe may be partly attributable to the inherent difficulties of targeting fibrillar amyloid plaques, which are not as well-defined as the soluble forms of the protein. Studies have shown that 
Fig. 3 The relationship between the contrast $(C)$ in a PET image and the differential uptake ratio $(D)$ of radiotracer uptake in targeted $\beta$-amyloid plaques to the background is represented linearly at three distinct stages of disease progression, where $C=f_{\mathrm{v}}(D-1)$ (see Appendix for details). Patients with MCI, early $\mathrm{AD}$, and late $\mathrm{AD}$ are assumed to have roughly $0.1 \%$, $1 \%$, and $6 \%$ of total cortical area (i.e., area fractions $f_{\mathrm{a}}$ ) occupied by $\beta$-amyloid, respectively, and corresponding volume fractions $\left(f_{\mathrm{v}}\right)$ of roughly $0.03 \%$, $0.33 \%$, and $2.0 \%$, respectively

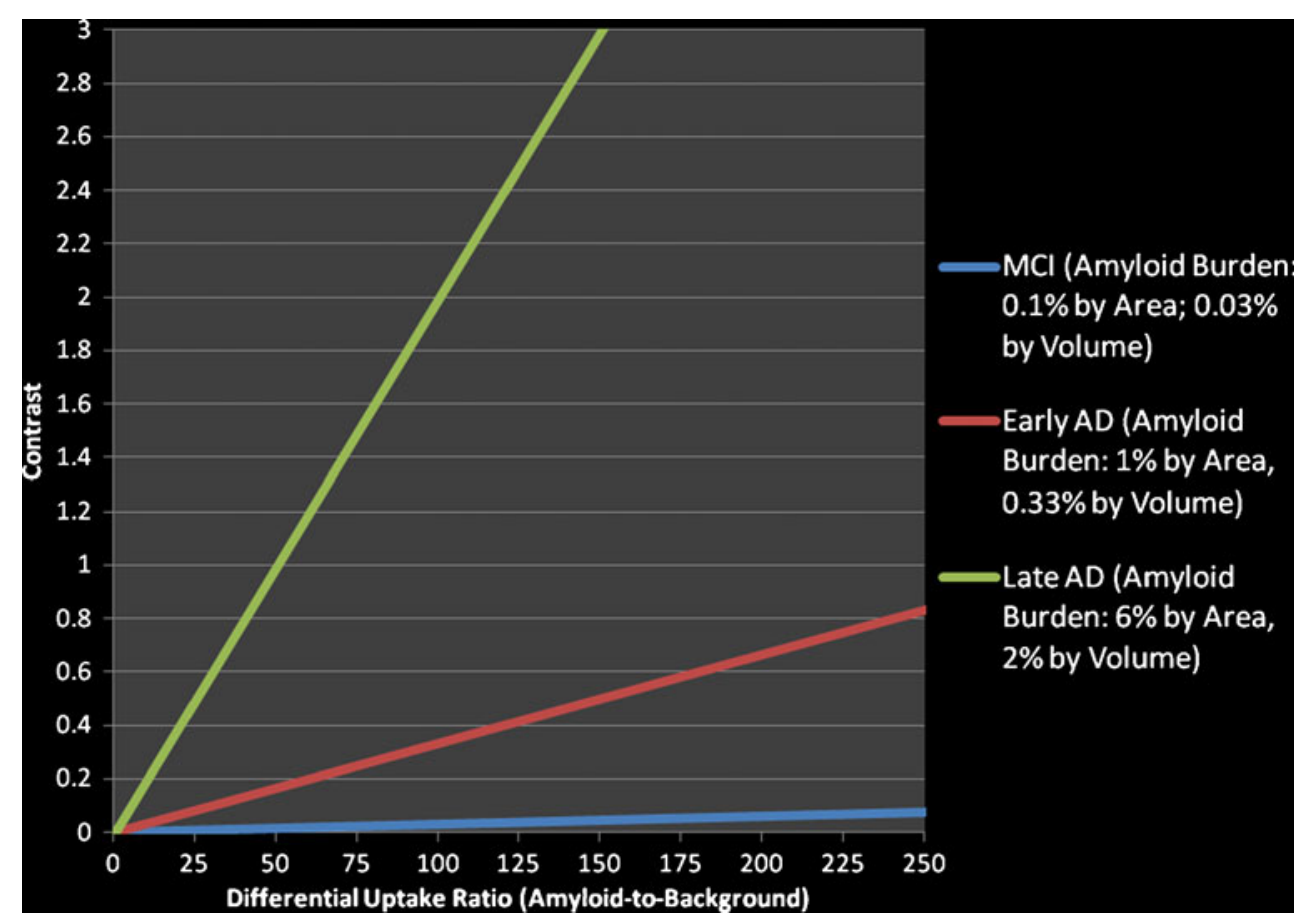

despite their ability to bind to $A \beta$ in fibrillar plaques and cerebral arteries, amyloid radiotracers such as $\left[{ }^{11} \mathrm{C}\right] \mathrm{PiB}$ have a low affinity for amorphous plaques in the cortices [39]. The possibility that $A \beta$ precipitates differently according to the region of the brain and the stage of the disease introduces the problem of disparate surface structures. This would pose a major challenge to the specificity of amyloid imaging agents, and should therefore be ruled out by performing in vivo dose-binding studies.

Autoradiographical binding studies have been performed on amyloid radiotracers to establish their specificity, but certain methodological oversights necessitate further in vivo testing to validate their conclusions [40]. A key contributor to the uncertainty surrounding binding specificity is the fact that while the development of imaging agents such as $\left[{ }^{11} \mathrm{C}\right] \mathrm{PiB}$ accounted for the microdoses that would ultimately reach the targeted proteins in vivo, binding studies were performed ex vivo in a medium that had an excess of the radiotracer [31, 40, 42]. This difference in dosage serves as a confounding variable that hinders the conclusiveness of the binding studies that have been performed thus far.

\section{Theoretical basis of amyloid imaging}

In addition to these practical concerns regarding amyloid radiotracers, there is the broader issue of the theoretical underpinnings of amyloid imaging. The ability of this technique to diagnose early $\mathrm{AD}$ rests upon the assumption that $A \beta$ plays an etiological role in the progression of the disease, for the density of a non-etiological biomarker would not necessarily be correlated with cognitive decline. This is precisely what was found by Bennett et al. in the frontal cortex of $\mathrm{AD}$ patients, where amyloid plaque burden did not reflect dementia severity [43]. This raises the point that while the correlation between $\mathrm{A} \beta$ and $\mathrm{AD}$ is well

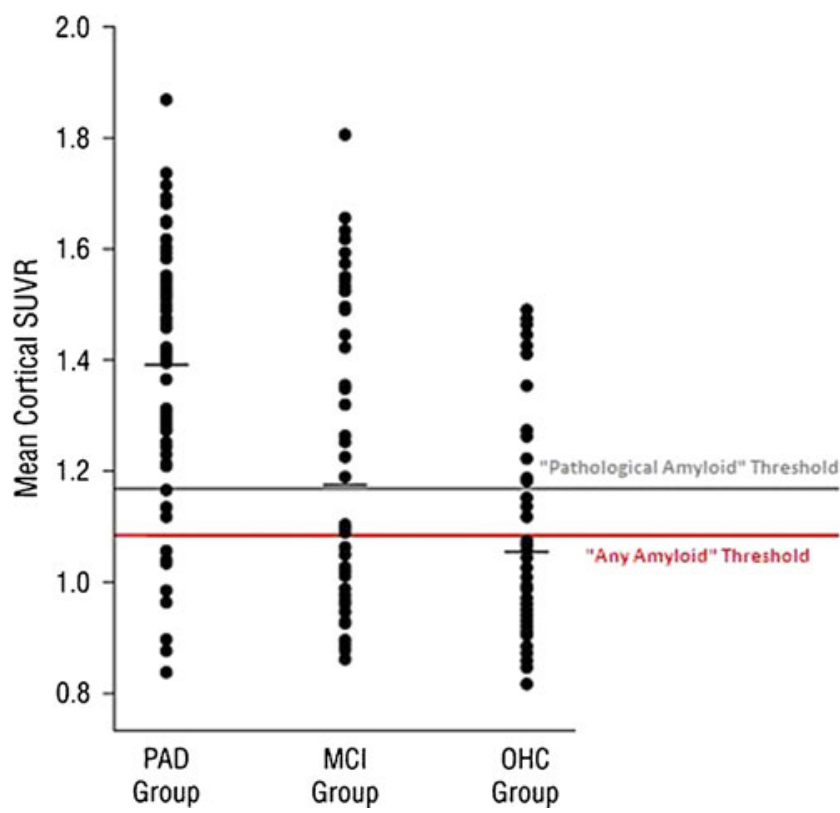

Fig. 4 A scatterplot of mean cortical SUV ratios in individuals with probable $\mathrm{AD}(P A D)$ and mild cognitive impairment $(M C I)$, as well as older healthy controls $(\mathrm{OHC})$ [8]. Noteworthy false-negative and false-positive rates can be seen in $\mathrm{AD}$ patients and controls, respectively (reproduced with permission from Archives of Neurology, [8]) 
established, the claim of causation is still a matter of debate and has recently been challenged by developments in the clinical trials of antiamyloid pharmaceuticals.

Drugs and vaccines that reached the latter stages of FDA testing, such as tramiprosate, tarenflurbil, bapineuzumab, semagacestat, and AN-1792, often proved exceptionally effective at reducing $A \beta$ burden in the brain, but ultimately failed to demonstrate a significant slowdown in cognitive decline when compared to controls [44-52]. Furthermore, the literature reveals that $10-20 \%$ of patients with clinically diagnosed $\mathrm{AD}$ do not have amyloid pathology at autopsy, and that $15-20 \%$ of $\mathrm{A} \beta$-positive PET scans are seen in subjects with no cognitive deficits. This is consistent with reports that significant $A \beta$ deposits can be found in the brain of cognitively normal elderly individuals at autopsy [42]. A possible implication of these findings is that $A \beta$ is not the direct cause of the synaptic and neuronal injury that triggers $\mathrm{AD}$, but is rather part of a larger cascade that dictates the disease process.

Viewing $A \beta$ in this light could explain the noteworthy rates of false-positive and false-negative PET scans using amyloid tracers $[53,54]$. Amyloid imaging with $\left[{ }^{11} \mathrm{C}\right] \mathrm{PiB}$ has revealed that over one-fifth of cognitively unimpaired individuals over the age of 65 years demonstrate uptake above a predetermined threshold for $\mathrm{AD}$ in at least one region of interest [55]. On the other hand, case studies in the literature reveal that subjects with declining cognitive function, positive tests for $\mathrm{AD}$ biomarkers in the cerebrospinal fluid, and positive pathological tests at autopsy can still demonstrate $\left[{ }^{11} \mathrm{C}\right] \mathrm{PiB}$ binding below detectable levels [39]. This was reflected in a recent study using florbetapir, which showed significant overlap between scans of patients with probable $\mathrm{AD}$, patients with MCI, and older healthy controls (Fig. 4) [8]. These observations severely limit the utility of this PET imaging approach for accurately diagnosing the presence or absence of MCI, let alone early AD.

\section{Conclusion}

Based on the extent of amyloid deposition in cognitively normal individuals and the inexplicably high degree of activity detected in the frontal lobe and white matter, it would appear that the claims made about the high degrees of sensitivity and specificity of amyloid imaging agents in detecting $\mathrm{AD}$ are not justifiable. When the pathologically established distribution of $\mathrm{A} \beta$ is taken into account, the probability of extensive nonspecific uptake by biological processes appears inescapably high. It is of paramount importance that such fundamental theoretical and practical concerns be thoroughly investigated and properly addressed before amyloid tracers enter the market en masse and expand the applications of amyloid imaging to the clinical field.
Financial support None.

\section{Appendix: Converting area fractions to volume fractions, and calculating the contrast produced by various differential uptake ratios and amyloid burdens}

The findings of the cited histopathological and immunohistochemical studies with data on the amyloid burden of $\mathrm{AD}$ patients are expressed as ratios of two-dimensional (2D) cross-sectional areas $\left(f_{\mathrm{a}}\right)$. However, since the voxels that comprise a PET image are three-dimensional cubes, these values have to be recalculated for three-dimensional volumes $\left(f_{\mathrm{v}}\right)$. Assuming that (1) the plaques are spherical with radius $R$, (2) the plaques are either completely or not at all within the 2D slice of thickness $T$ and area of interest $A$, and (3) that he 2D measurement accurately represents the widest cross section of the (spherical) plaque, the problem reduces to finding the number of plaques in the slice: $N=A f_{\mathrm{a}} /\left(\pi R^{2}\right)$. The volume fraction is then $f_{\mathrm{v}}=(4 / 3)$ $\pi R^{3} N /(A T)=(4 / 3)(R / T) f_{\mathrm{a}}$, which is dimensionless, just like $f_{\mathrm{a}}$. In this calculation, we take the average radius of the sphere to be $25 \mu \mathrm{m}$ [36].

Now assume that a voxel with no amyloid activity (i.e., background only) has unit concentration. Then a voxel on PET imaging containing amyloid activity can be segmented into the volume fraction for amyloid plaque $\left(f_{\mathrm{v}}\right)$, which has differential uptake ratio $D$, and the volume fraction without plaque $\left(1-f_{\mathrm{v}}\right)$, which has unit background activity. The total activity concentration (i.e., signal) for this voxel is $f_{\mathrm{v}} D+$ $\left(1-f_{\mathrm{v}}\right)$. Therefore, the contrast $C$ is given by (signalbackground)/background $=f_{\mathrm{v}}(\mathrm{D}-1)$.

\section{References}

1. Brookmeyer R, Johnson E, Ziegler-Graham K, Arrighi HM. Forecasting the global burden of Alzheimer's disease. Alzheimers Dement. 2007;3(3):186-91.

2. McKhann G, Drachman D, Folstein M, Katzman R, Price D, Stadlan EM. Clinical diagnosis of Alzheimer's disease: report of the NINCDS-ADRDA Work Group under the auspices of Department of Health and Human Services Task Force on Alzheimer's disease. Neurology. 1984;34(7):939-44.

3. Dubois B, Feldman HH, Jacova C, Dekosky ST, BarbergerGateau P, Cummings J, et al. Research criteria for the diagnosis of Alzheimer's disease: revising the NINCDS-ADRDA criteria. Lancet Neurol. 2007;6(8):734-46.

4. Khachaturian ZS. Diagnosis of Alzheimer's disease. Arch Neurol. 1985;42(11):1097-105.

5. Hardy J, Selkoe DJ. The amyloid hypothesis of Alzheimer's disease: progress and problems on the road to therapeutics. Science. 2002;297(5580):353-6.

6. Wong DF, Rosenberg PB, Zhou Y, Kumar A, Raymont V, Ravert HT, et al. In vivo imaging of amyloid deposition in Alzheimer disease using the radioligand 18F-AV-45 (Florbetapir F18). J Nucl Med. 2010;51(6):913-20. 
7. Clark CM, Schneider JA, Bedell BJ, Beach TG, Bilker WB, Mintun MA, et al. Use of florbetapir-PET for imaging $\beta$-amyloid pathology. JAMA. 2011;305(3):275-83.

8. Fleisher AS, Chen K, Liu X, Roontiva A, Thiyyagura $\mathrm{P}$, Ayutyanont $\mathrm{N}$, et al. Using positron emission tomography and florbetapir F18 to image cortical amyloid in patients with mild cognitive impairment or dementia due to Alzheimer disease. Arch Neurol. 2011. http://archneur.ama-assn.org/cgi/content/full/ archneurol.2011.150v1. Accessed 4 October 2011.

9. Barthel H, Gertz HJ, Dresel S, Peters O, Bartenstein P, Buerger K, et al. Cerebral amyloid- $\beta$ PET with florbetaben $(18 \mathrm{~F})$ in patients with Alzheimer's disease and healthy controls: a multicenter phase 2 diagnostic study. Lancet Neurol. 2011;10 (5):424-35.

10. Villemagne VL, Ong K, Mulligan RS, Holl G, Pejoska S, Jones G, et al. Amyloid imaging with (18)F-florbetaben in Alzheimer disease and other dementias. J Nucl Med. 2011;52(8):1210-7.

11. Vandenberghe R, Van Laere K, Ivanoiu A, Salmon E, Bastin C, Triau E, et al. 18F-Flutemetamol amyloid imaging in Alzheimer disease and mild cognitive impairment: a phase 2 trial. Ann Neurol. 2010;68(3):319-29.

12. Barthel H, Luthardt J, Becker G, Patt M, Hammerstein E, Hartwig $\mathrm{K}$, et al. Individualized quantification of brain $\beta$-amyloid burden: results of a proof of mechanism phase 0 florbetaben PET trial in patients with Alzheimer's disease and healthy controls. Eur J Nucl Med Mol Imaging. 2011;38(9):1702-14.

13. Kemppainen NM, Aalto S, Wilson IA, Nagren K, Helin S, Bruck A, et al. PET amyloid ligand [11C]PIB uptake is increased in mild cognitive impairment. Neurology. 2007;68(19):1603-6.

14. Kemppainen NM, Aalto S, Wilson IA, Nagren K, Helin S, Bruck A, et al. Voxel-based analysis of PET amyloid ligand [11C]PIB uptake in Alzheimer disease. Neurology. 2006;67(9):1575-80.

15. Arnold SE, Hyman BT, Flory J, Damasio AR, Van Hoesen GW. The topographical and neuroanatomical distribution of neurofibrillary tangles and neuritic plaques in the cerebral cortex of patients with Alzheimer's disease. Cereb Cortex. 1991;1(1):103-16.

16. Braak H, Braak E. Frequency of stages of Alzheimer-related lesions in different age categories. Neurobiol Aging. 1997;18 (4):351-7.

17. Brun A, Gustafson L. Distribution of cerebral degeneration of Alzheimer's disease. Arch Psychiatr Nervenkr. 1976;223(1):1533

18. Shin J, Kepe V, Small GW, Phelps ME, Barrio JR. Multimodal imaging of Alzheimer pathophysiology in the brain's default mode network. Int J Alzheimers Dis. 2011:687945.

19. Scahill RI, Schott JM, Stevens JM, Rossor MN, Fox NC. Mapping the evolution of regional atrophy in Alzheimer's disease: unbiased analysis of fluid-registered serial MRI. Proc Natl Acad Sci U S A. 2002;99(7):4703-7.

20. Thompson PM, Hayashi KM, de Zubicaray G, Janke AL, Rose SE, Semple J, et al. Dynamics of gray matter loss in Alzheimer's disease. J Neurosci. 2003;23(3):994-1005.

21. Yetkin FZ, Rosenberg RN, Weiner MF, Purdy PD, Cullum CM. FMRI of working memory in patients with mild cognitive impairment and probable Alzheimer's disease. Eur Radiol. 2006;16(1):193-206.

22. Mosconi L, Tsui WH, Herholz K, Pupi A, Drzezga A, Lucignani $\mathrm{G}$, et al. Multicenter standardized 18F-FDG PET diagnosis of mild cognitive impairment, Alzheimer's disease, and other dementias. J Nucl Med. 2008;49(3):390-8.

23. Herholz K, Salmon E, Perani DBaron JC, Holthoff V, Frolich L, et al. Discrimination between Alzheimer dementia and controls by automated analysis of multicenter FDG PET. Neuroimage. 2002;17(1):302-16.

24. Furst AJ, Lal RA. Amyloid-B and Glucose Metabolism in Alzheimer's Disease. J Alzheimers Dis. 2011;26:105-16.
25. Attems J, Quass M, Jellinger KA, Lintner F. Topographical distribution of cerebral amyloid angiopathy and its effect on cognitive decline are influenced by Alzheimer disease pathology. J Neurol Sci. 2007;257(1-2):49-55.

26. Xu D, Yang C, Wang L. Cerebral amyloid angiopathy in aged Chinese: a clinic-neuropathological study. Acta Neuropathol. 2003;106(1):89-91.

27. $\mathrm{Ti} \mathrm{M}$. The incidence of cerebral amyloid angiopathy in Alzheimer's disease. Neurology. 1975;25(2):120-6.

28. Ellis RJ, Olichney JM, Thal LJ, Mirra SS, Morris JC, Beekly D, et al. Cerebral amyloid angiopathy in the brains of patients with Alzheimer's disease. Neurology. 1996;46(6):1592-6.

29. Esiri MM, Wilcock GK. Cerebral amyloid angiopathy in dementia and old age. J Neurol Neurosurg Psychiatry. 1986;49 (11):1221-6.

30. Fodero-Tavoletti MT, Rowe CC, McLean CA, Leone L, Li QX, Masters CL, et al. Characterization of $\mathrm{PiB}$ binding to white matter in Alzheimer disease and other dementias. J Nucl Med. 2009;50 (2):198-204.

31. Klunk WE, Engler H, Nordberg A, Wang Y, Blomqvist G, Holt DP, et al. Imaging brain amyloid in Alzheimer's disease with Pittsburgh Compound-B. Ann Neurol. 2004;55(3):306-19.

32. Blomquist G, Engler H, Nordberg A, Ringheim A, Wall A, Forsberg A, et al. Unidirectional influx and net accumulation of PIB. Open Neuroimaging J. 2008;2:114-25.

33. Thomas BA, Erlandsson K, Modat M, Thurfjell L, Vandenberghe $\mathrm{R}$, Ourselin S, et al. The importance of appropriate partial volume correction for PET quantification in Alzheimer's disease. Eur J Nucl Med Mol Imaging. 2011;38(6):1104-19.

34. Hickeson M, Yun M, Matthies A, Zhuang H, Adam LE, Lacorte $\mathrm{L}$, et al. Use of corrected standardized uptake value based on the lesion size on CT permits accurate characterization of lung nodules on FDG-PET. Eur J Nucl Med Mol Imaging. 2002;29 (12):1639-47.

35. Kessler RM, Ellis JR, Eden M. Analysis of emission tomographic scan data: limitations imposed by resolution and background. $\mathrm{J}$ Comput Assist Tomogr. 1984;8(3):514-22.

36. Connor DM, Benveniste H, Dilmanian FA, Kritzer MF, Miller LM, Zhong Z. Computed tomography of amyloid plaques in a mouse model of Alzheimer's disease using diffraction enhanced imaging. Neuroimage. 2009;46(4):908-14.

37. Sanchez-Crespo A, Andreo P, Larsson SA. Positron flight in human tissues and its influence on PET image spatial resolution. Eur J Nucl Med Mol Imaging. 2004;31(1):44-51.

38. Bussiere T, Friend PD, Sadeghi N, Wicinski B, Lin GI, Bouras C, et al. Stereologic assessment of the total cortical volume occupied by amyloid deposits and its relationship with cognitive status in aging and Alzheimer's disease. Neuroscience. 2002;112(1):75-91.

39. Cairns NJ, Ikonomovic MD, Benzinger T, Storandt M, Fagan AM, Shah AR, et al. Absence of Pittsburgh compound B detection of cerebral amyloid beta in patient with Alzheimer disease: a case report. Arch Neurol. 2009;66(12):1557-62.

40. Lin KJ, Hsu WC, Hsiao IT, Wey SP, Jin LW, Skovronsky D, et al. Whole-body biodistribution and brain PET imaging with [18F] AV-45, a novel amyloid imaging agent - a pilot study. Nucl Med Biol. 2010;37(4):497-508.

41. Bergström M, Grahnén A, Långström B. Positron emission tomography microdosing: a new concept with application in tracer and early clinical drug development. Eur J Clin Pharmacol. 2003;59(5-6):357-66.

42. Lister-James J, Pontecorvo MJ, Clark C, Joshi AD, Mintun MA, Zhang W, et al. Florbetapir F-18: a histopathologically validated beta-amyloid positron emission tomography imaging agent. Semin Nucl Med. 2011;41(4):300-4.

43. Bennett DA, Cochran EJ, Saper CB, Leverenz JB, Gilley DW, Wilson RS. Pathological changes in frontal cortex from biopsy to 
autopsy in Alzheimer's disease. Neurobiol Aging. 1993;14 (6):589-96.

44. Aisen PS, Gauthier S, Ferris SH, Saumier D, Haine D, Garceau D, et al. Tramiprosate in mild-to-moderate Alzheimer's disease - a randomized, double-blind, placebo-controlled, multi-centre study (the Alphase Study). Arch Med Sci. 2011;7(1):102-11.

45. Green RC, Schneider LS, Amato DA, Beelen AP, Wilcock G, Swabb EA, et al. Effect of tarenflurbil on cognitive decline and activities of daily living in patients with mild Alzheimer disease: a randomized control trial. JAMA. 2009;302(23):2557-64.

46. Salloway S, Sperling R, Gilman S, Fox NC, Blennow K, Raskind $\mathrm{M}$, et al. A phase 2 multiple ascending dose trial of bapineuzumab in mild to moderate Alzheimer disease. Neurology. 2009;73 (24):2061-70.

47. Panza F, Frisardi V, Imbimbo BP, D’Onofrio G, Pietrarossa G, Seripa D, et al. Bapineuzumab: anti- $\beta$-amyloid monoclonal antibodies for the treatment of Alzheimer's disease. Immunotherapy. 2010;2(6):767-82.

48. Imbimbo BP, Panza F, Frisardi V, Solfrizzi V, D’Onofrio G, Logroscino $G$, et al. Therapeutic intervention for Alzheimer's disease with $\gamma$-secretase inhibitors: still a viable option?. Expert Opin Investig Drugs. 2011;20(3):325-41.
49. Robinson SR, Bishop GM, Lee HG, Munch G. Lessons from the AN 1792 Alzheimer vaccine: lest we forget. Neurobiol Aging. 2004;25(5):609-15.

50. Munch G, Robinson SR. Alzheimer's vaccine: a cure as dangerous as the disease? J Neural Transm. 2002;109(4):537-9.

51. Rafii MS, Aisen PS. Recent developments in Alzheimer's disease therapeutics. BMC Med. 2009;7:7.

52. Sabbagh MN. Drug development for Alzheimer's disease: where are we now and where are we headed?. Am J Geriatr Pharmacother. 2009;7(3):167-85.

53. Mayeux R, Saunders AM, Shea S, Mirra S, Evans D, Roses AD, et al. Utility of the apolipoprotein E genotype in the diagnosis of Alzheimer's disease. Alzheimer's Disease Centers Consortium on Apolipoprotein E and Alzheimer's Disease. N Engl J Med. 1998;338(8):506-11.

54. Ranginwala NA, Hynan LS, Weiner MF, White III CL. Clinical criteria for the diagnosis of Alzheimer disease: still good after all these years. Am J Geriatr Psychiatry. 2008;18(5):384-8.

55. Aizenstein HJ, Nebes RD, Saxton JA, Price JC, Mathis CA, Tsopelas ND, et al. Frequent amyloid deposition without significant cognitive impairment among the elderly. Arch Neurol. 2008;65(11):1509-17. 